\title{
Can the Impact of the Excessive Use of Salt and its Chronic Consequences be Atenuated by Functional Foods?
}

\author{
Juliana Tomaz Pacheco Latini ${ }^{(\mathbb{1})}$ and Kátia Calvi Lenzi de Almeida \\ Universidade Federal do Rio de Janeiro/Campus Macaé, Rio de Janeiro, RJ - Brazil. \\ Editorial referring to the article: Maternal Intake of Flaxseed During Lactation and Exercise Training Protect Against Salt Overload-Induced \\ Aortic Remodeling in Adult Offspring
}

Significant evidence has been showing the strong impact that food has on health. Among the substances that have a great influence on food choices and preferences is sodium (salt), ${ }_{1}^{1}$ which has been associated with obesity and chronic diseases, such as diabetes mellitus, high blood pressure and cardiovascular diseases. ${ }^{2,3}$

According to National Academies of Sciences, Engineering and Medicine (2019), ${ }^{4}$ a sodium intake below $2.3 \mathrm{~g} /$ day is recommended for adults to reduce the risk of chronic diseases, such as high blood pressure. Despite great educational efforts on the part of government and medical authorities, populations still maintain a higher than recommended sodium intake, ${ }^{5}$ which has led to the development of public health strategies to reduce this problem.

Obesity and excessive adiposity are also important risk factors for the development of high blood pressure. In addition, genetic factors, inflammatory processes, oxidative stress, vascular and cardiac smooth muscle dysfunction and, especially, endothelial dysfunction are also strongly associated with the development of this chronic disease. ${ }^{6}$

Endothelial dysfunction is characterized by a list of changes in the endothelium that promote a reduction in vasodilation, pro-inflammatory state, detachment and apoptosis of endothelial cells and the development of atherosclerosis. Structural and inflammatory cells produce inflammatory mediators, such as certain lipids, free radicals, cytokines, chemokines and growth factors. However, the number of these mediators is high during the development of some diseases, such as obesity and high blood pressure, reaching the circulation and leading to systemic inflammation and,

\section{Keywords}

Sodium Chloride; Sodium; Flax; Funcional Food; Obesity; Diabetes Mellitus; Hypertension. via the vasculature potentiating endothelial dysfunction, ${ }^{7}$ contributing to the aortic and/or cardiac remodeling.

Endothelial integrity depends not only on the extent of the injury, but also on the endogenous repair capacity. More recently, it has become clear that circulating endothelial progenitor cells are an important alternative mechanism for maintenance and repair of the endothelium. The mobilization of these cells is partly NO-dependent and may be impaired in patients with cardiovascular risk factors. Likewise, factors that have been shown to lead to improved endothelial function and NObioavailability, such as exercise and the use of statins, have also been shown to have a powerful positive effect on the mobilization of endothelial progenitor cells. ${ }^{8}$

However, in addition to the practice of physical activity and the use of medications, it is postulated that different dietary interventions and approaches are necessary to minimize or prevent the chronic process characteristic of high blood pressure, as well as to prevent it. In addition to reducing sodium consumption, the beneficial use of functional and nutraceutical foods stands out as adjunctive therapies to pharmacotherapy for the treatment of this disease and its consequences. ${ }^{9}$

Studies have shown that flaxseed, a functional food that has a high content of fibers and essential fatty acids such as omega-3, has antihypertensive, anti-diabetic, antiinflammatory and anticancer effects, mainly attributed to the activity of Secoisolariciresinol Diglicoside (SDG). The experimental study conducted by Silva-Couto et al., ${ }^{10}$ points out that it is possible to mitigate the impact caused on health by the large consumption of salt, attributed to nutritional intervention with flaxseed. We invite you to read this article, where the reader can glimpse the interesting results about the use of this functional food in the prevention of aortic remodeling related to excessive use of sodium. Good reading!

Mailing Address: Juliana Latini

Rua Alcides da Conceição, 159. Postal Code: 27.933-379, Macaé, Rio de Janeiro, RJ - Brazil.

E-mail: julianatomaz@yahoo.com.br 


\section{References}

1. Duffy VB, Hayes JE, Sullivan BS, Faghri P. Surveying food and beverage liking: a tool for epidemiological studies to connect chemosensation with health outcomes. Ann N Y Acad Sci. 2009; 1170:558-68.

2. Meneton $P$, Jeunemaitre $X$, de Wardener HE, MacGregor GA. Links between dietary salt intake, renal salt handling, blood pressure, and cardiovascular diseases. Physiol Rev. 2005; 85(2):679-715

3. Moosavian SP, Haghighatdoost F, Surkan PJ, Azadbakht L. Salt and obesity: a systematic review and meta-analysis of observational studies. Int J Food Sci Nutr. 2017; 68(3):265-77

4. National Academies of Sciences, Engineering, and Medicine 2019. Dietary Reference Intakes for Sodium and Potassium. Washington, DC: The National Academies Press.[Cited in 2019 Oct 21] Available at https:// doi.org/10.17226/25353.

5. Thout SR, Santos JA, McKenzie B, Trieu K, Johnson C, McLean R, et al. The Science of Salt: Updating the evidence on global estimates of salt intake. J Clin Hypertens (Greenwich). 2019; 21(6):710-721. doi: 10.1111/ jch.13546.
6. Butler MG. Pediatric hypertension: genetics of hypertension current status. Le Journal medical libanais. Leban Med J. 2010; 58(3): 175-8.

7. Szucs B, Szucs C, Petrekanits M, Varga JT. Molecular Characteristics and Treatment of Endothelial Dysfunction in Patients with COPD: A Review Article. Int J Mol Sci. 2019; 20(18):4329. doi: 10.3390/ijms20184329.

8. Giribela CRG, Gengo R, Hong V, Consolim-Colombo FM. Função e disfunção endotelial: da fisiopatologia às perspectivas de uso em pesquisa e na prática clínica Rev Bras Hipertens. 2011; 18(1):27-32.

9. Ghaffari S, Roshanravan N. The role of nutraceuticals in prevention and treatment of hypertension: An updated review of the literature. Food Res Int. 2020; 128:108749. doi: 10.1016/j.foodres.2019.108749.

10. Couto SS, Correia-Santos AM, Vicente GC, Castro CLC, Barreto VLM, Martins JEC,et al. Maternal Intake of Flaxseed During Lactation and Exercise Training Protect Against Salt Overload-Induced Aortic Remodeling in Adult Offspring. Int J Cardiovasc Sci. 2021; 34(2):124-133. 